NASA/TM-2001-211094

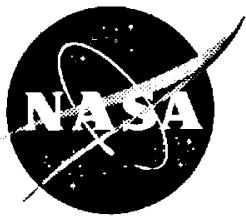

\title{
Adaptive Vibration Reduction Controls for a Cryocooler With a Passive Balancer
}

George Kopasakis and James E. Cairelli

Glenn Research Center, Cleveland, Ohio

Ryan M. Traylor

Purdue University, West Lafayette, Indiana 
Since its founding, NASA has been dedicated to the advancement of aeronautics and space science. The NASA Scientific and Technical Information (STI) Program Office plays a key part in helping NASA maintain this important role.

The NASA STI Program Office is operated by Langley Research Center, the Lead Center for NASA's scientific and technical information. The NASA STI Program Office provides access to the NASA STI Database, the largest collection of aeronautical and space science STI in the world. The Program Office is also NASA's institutional mechanism for disseminating the results of its research and development activities. These results are published by NASA in the NASA STI Report Series, which includes the following report types:

- TECHNICAL PUBLICATION. Reports of completed research or a major significant phase of research that present the results of NASA programs and include extensive data or theoretical analysis. Includes compilations of significant scientific and technical data and information deemed to be of continuing reference value. NASA's counterpart of peerreviewed formal professional papers but has less stringent limitations on manuscript length and extent of graphic presentations.

- TECHNICAL MEMORANDUM. Scientific and technical findings that are preliminary or of specialized interest, e.g., quick release reports, working papers, and bibliographies that contain minimal annotation. Does not contain extensive analysis.

- CONTRACTOR REPORT. Scientific and technical findings by NASA-sponsored contractors and grantees.
- CONFERENCE PUBLICATION. Collected papers from scientific and technical conferences, symposia, seminars, or other meetings sponsored or cosponsored by NASA.

- SPECIAL PUBLICATION. Scientific, technical, or historical information from NASA programs, projects, and missions, often concerned with subjects having substantial public interest.

- TECHNICAL TRANSLATION. Englishlanguage translations of foreign scientific and technical material pertinent to NASA's mission.

Specialized services that complement the STI Program Office's diverse offerings include creating custom thesauri, building customized data bases, organizing and publishing research results ... even providing videos.

For more information about the NASA STI Program Office, see the following:

- Access the NASA STI Program Home Page at http://www.sti.nasa.gov

- E-mail your question via the Internet to help@sti.nasa.gov

- Fax your question to the NASA Access Help Desk at 301-621-0134

- Telephone the NASA Access Help Desk at 301-621-0390

- Write to: NASA Access Help Desk NASA Center for AeroSpace Information 7121 Standard Drive Hanover, MD 21076 
NASA/TM-2001-211094

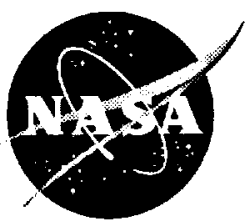

\section{Adaptive Vibration Reduction Controls for a Cryocooler With a Passive Balancer}

George Kopasakis and James E. Cairelli

Glenn Research Center, Cleveland, Ohio

Ryan M. Traylor

Purdue University, West Lafayette, Indiana

Prepared for the

2001 Cryogenic Engineering Conference (CEC) and

International Cryogenic Materials Conference (ICMC)

sponsored by the Cryogenic Society of America

Madison, Wisconsin, July 16-20, 2001

National Aeronautics and

Space Administration

Glenn Research Center 


\section{Acknowledgments}

The authors are grateful to Joe Saus and Timothy Regan for their constructive review of this work.

Available from

NASA Center for Aerospace Information 7121 Standard Drive

Hanover, MD 21076
National Technical Information Service 5285 Port Royal Road Springfield, VA 22100

Available electronically at http://gltrs.grc.nasa.gov/GLTRS 


\title{
ADAPTIVE VIBRATION REDUCTION CONTROLS FOR A CRYOCOOLER WITH A PASSIVE BALANCER
}

\author{
George Kopasakis and James E. Cairell \\ National Aeronautics and Space Administration \\ Glenn Research Center \\ Cleveland, Ohio 44135 \\ Ryan M. Traylor \\ Purdue University \\ West Lafayette, Indiana 47907
}

\begin{abstract}
In this paper an adaptive vibration reduction control (AVRC) design is described for a Stirling cryocooler combined with a passive balancer. The AVRC design was based on a massspring model of the cooler and balancer, and the AVRC algorithm described in this paper was based on an adaptive binary search. Results are shown comparing the baseline uncontrolled cooler with no balancer, the cooler with the balancer, and, finally, the cooler with the balancer and the AVRC. The comparison shows that it may be possible to meet stringent vibration reduction requirements without an active balancer.
\end{abstract}

\section{INTRODUCTION}

The work described herein was supported by the Space Solar Power (SSP) project to conduct initial cryocooler characterization studies. The SSP project proposes the use of large fields of solar arrays in space to produce power, which would then be transmitted to Earth receiving stations in microwave beams. The cables in this power distribution system are to be cooled at superconducting temperatures. However, cryocooler vibrations that put mechanical stresses on the cables could cause loss of superconductivity, resulting in catastrophic failures.

At NASA Glenn Research Center, a cryocooler testbed has been built to address cryocooler performance in terms of power, temperature, vibrations, mounting techniques, and heat rejection. Of particular importance is the cooler's vibration performance, since a variety of cryocooler applications require a reduction in vibration levels. The purpose of the vibration work at NASA Glenn is to establish a methodology for controlling cryocooler vibrations with a reduced parts count. Also, the controls must be adaptive because vibration dynamics are expected to change over time. 
Another important consideration for reducing transmitted vibration forces is the selection of cryocooler mounting. Work is also in progress on designing and investigating cryocooler soft mounting techniques, but this area of study is beyond the scope of this paper. The cooler used in this testbed (Global Cooling Manufacturing Co., Athens, Ohio) can operate only down to about $-120^{\circ} \mathrm{C}$. However, in terms of vibrations, the dynamics of this cooler are similar to coolers operating at superconducting temperatures.

This paper describes the cryocooler testbed at NASA Glenn and presents a derivation of the cooler mass-spring dynamics. An overview of the adaptive vibration reduction control (AVRC) design is also presented. For comparison, test data from the implemented passive balancer and AVRC control with baseline data from the uncontrolled cooler with no balancer are also presented.

\section{CRYOCOOLER TESTBED}

The cryocooler testbed diagram is shown schematically in Figure 1 and pictorially in Figure 2. As seen in Figure 2, the cryocooler is surrounded by insulation on the cold tip to maintain cooling, and the balancer-accelerometer transducer is mounted at the end of the exposed part of the cooler. The control functions and parameter monitoring are performed through a computer using LabVIEW (National Instruments Corporation, Austin, Texas) application software. One cycle of the desired waveform is loaded onto a General Purpose Interface Bus (GPIB) 488.2 to the arbitrary waveform generator. The waveform generator continuously outputs the loaded signal until one cycle of a new waveform is downloaded. The waveform generator starts outputting the new waveform after it completes the current cycle of the old waveform (at zero). This allows for a seamless transition while updating a synthesized waveform for control purposes. The output of the waveform generator is connected to a

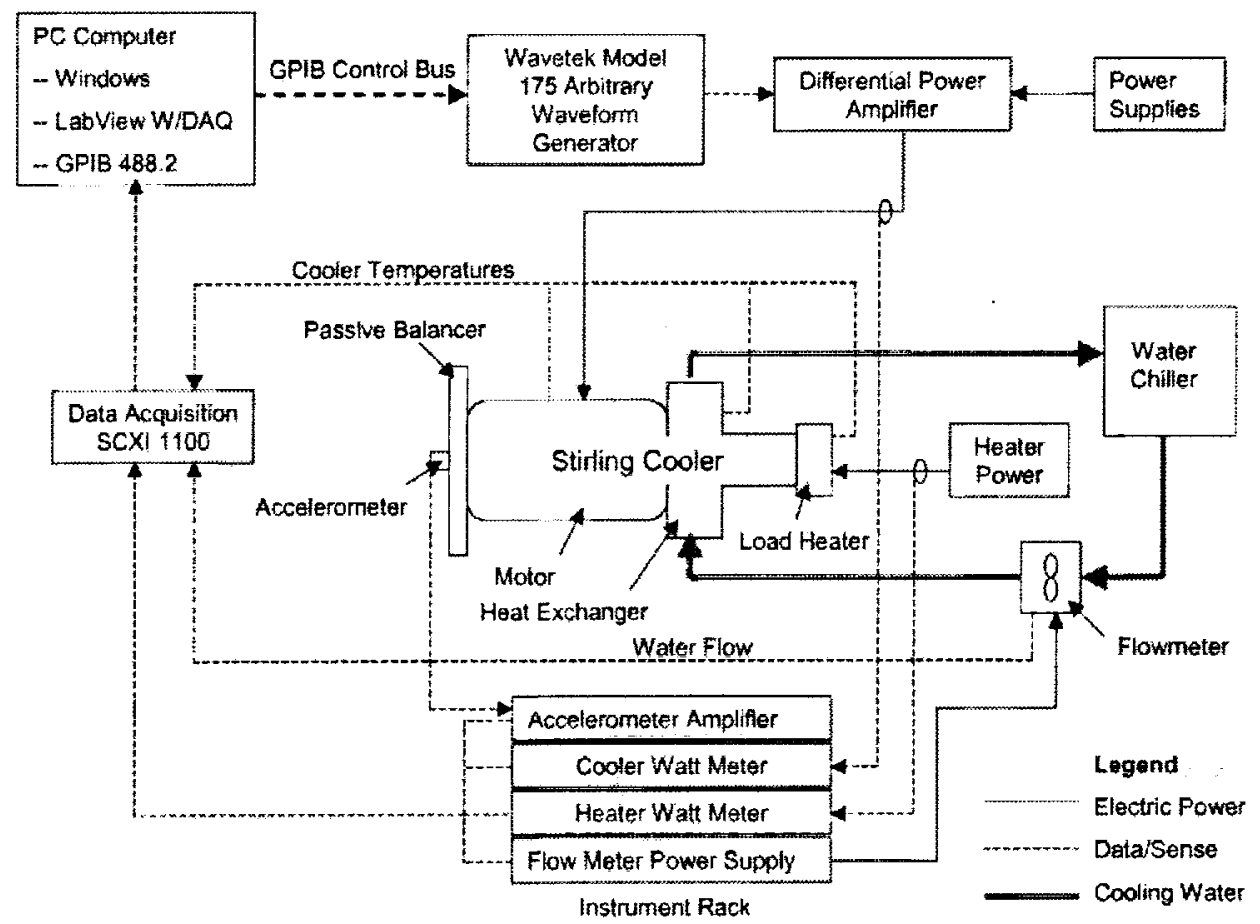

FIGURE 1. Cryocooler testbed configuration diagram. 

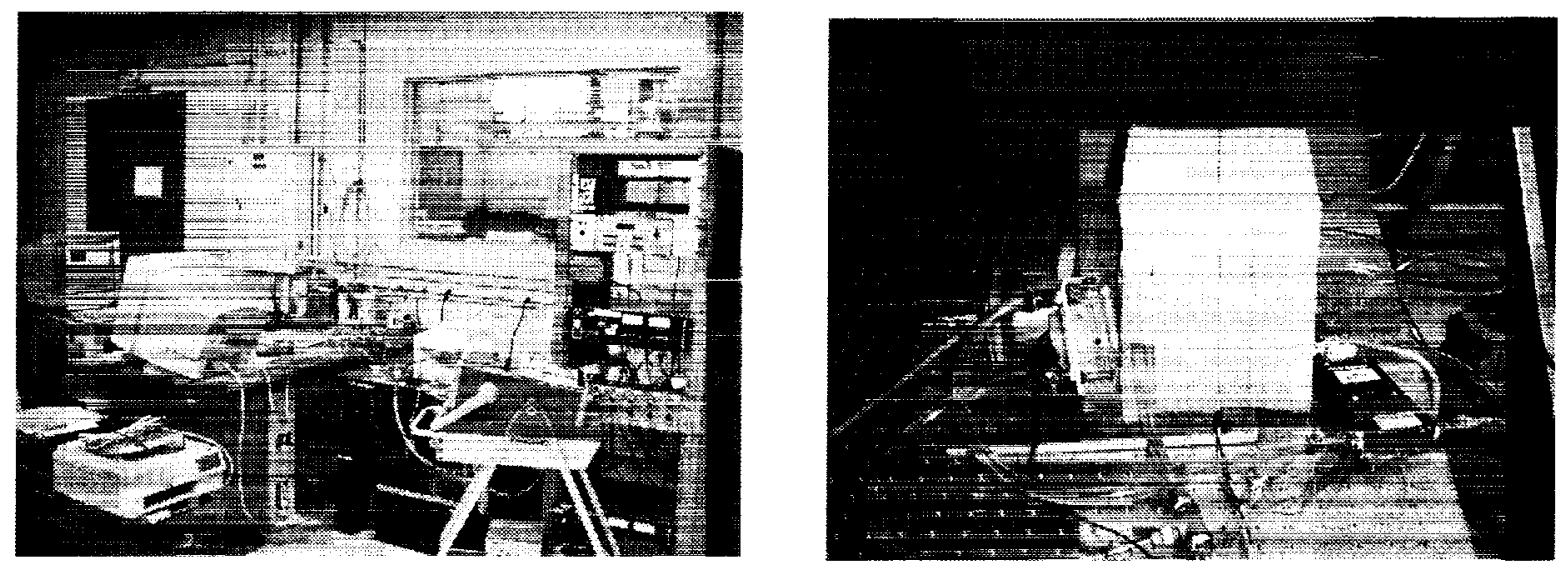

FIGURE 2. Cryocooler testbed.

differential power amplifier, which drives the cooler. This power amplifier was also designed and built for this project. The computer generates the cooler power drive signal, as well as the vibration cancellation signal, and the two signals are superimposed to finally drive the power amplifier. Acceleration measurements are taken with the accelerometer amplifier from the accelerometer transducer and used for vibration control. The passive balancer is attached to the cryocooler to dampen vibrations. Other parameters being monitored include temperatures, current, voltages, and chiller water flow. With soft mounting, the cryocooler rests on a vibration isolation table to isolate it from facility-induced vibrations, as shown in Figure 2.

\section{CRYOCOOLER MASS-SPRING MODEL}

In this study, a two-mass-spring system model for the cryocooler-balancer was developed to gain insight on the general system dynamic behavior for vibration control, transmitted force, and the design of a soft-mounting cryocooler assembly.

The cryocooler-balancer two-mass-spring system shown in Figure 3 can be mathematically described with the following system of differential equations [1]:

$$
\begin{gathered}
m_{1} \ddot{x}_{1}+c \dot{x}_{1}+k_{1} x_{1}-k_{2}\left(x_{2}-x_{1}\right)=F \\
m_{2} \ddot{x}_{2}+k_{2}\left(x_{2}-x_{1}\right)=0
\end{gathered}
$$

where $m_{1}, m_{2}$ are the cryocooler and balancer mass; $x_{1}, x_{2}$ are the cooler and balancer translation distance in the cooler axial direction; $k_{1}, k_{2}$ are the cooler to the external interface and the balancer to the cooler spring constants; $c$ is the cooler to the external interface damping; and $F$ is the cooler unbalanced force (typically sinusoidal).

This unbalanced force has its fundamental component at the power drive frequency with its respective higher order harmonics. Computing the Laplace transform of equation (2) gives

$$
\frac{X_{2}(s)}{X_{1}(s)}=\frac{\omega_{2}^{2}}{s^{2}+\omega_{2}^{2}}
$$




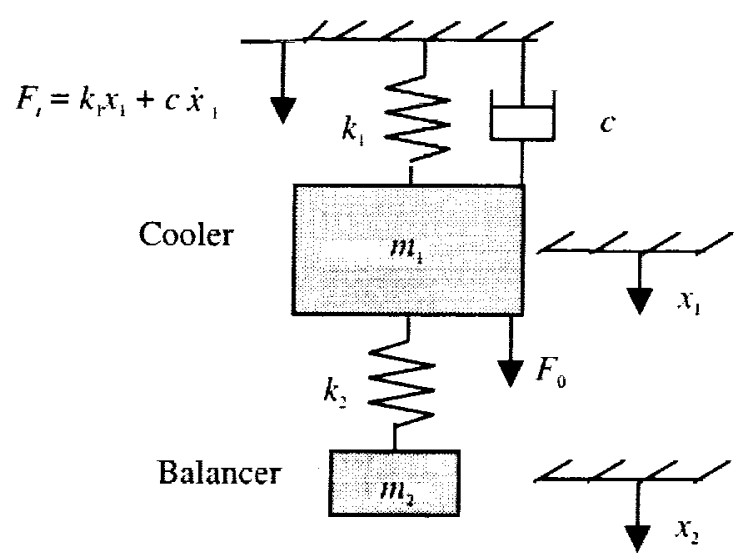

FIGURE 3. Cooler-balancer mass-spring system.

where $\omega_{2}=\sqrt{k_{2} / m_{2}}$. Dividing both sides of equation (1) by $k_{1}$, computing its Laplace transform, and substituting the expression of $X_{2}(s)$ from (3) gives

$$
\frac{m_{1}}{k_{1}} s^{2} X_{1}(s)+\frac{c}{k_{1}} s X_{1}(s)+\left(1+\frac{k_{2}}{k_{1}}\right) X_{1}(s)-\frac{\left(k_{2} k_{1}\right) \omega_{2}^{2}}{s^{2}+\omega_{2}^{2}} X_{1}(s)=\frac{F_{0}}{k_{1}}
$$

where. $F_{0}=m_{1} g$. Substituting the expressions $\omega_{1}=\sqrt{k_{1} / m_{1}}$ and the deflection $X_{0}=F_{0} / k_{1}$ in equation (4), multiplying both sides by the expression $\left(s^{2}+\omega_{2}^{2}\right)$, and grouping similar terms gives

$$
\begin{gathered}
\frac{X_{1}(s)}{X_{0}(s)}=\frac{\omega_{1}^{2}\left(s^{2}+\omega_{2}^{2}\right)}{s^{4}+\frac{c}{m_{1}} s^{3}+\left(\omega_{2}^{2}+\omega_{1}^{2}+\frac{m_{2}}{m_{1}} \omega_{2}^{2}\right) s^{2}+\frac{c}{m_{1}} \omega_{2}^{2} s+\left(\omega_{1} \omega_{2}\right)^{2}} \\
\frac{X_{2}(s)}{X_{0}(s)}=\frac{X_{1}(s)}{X_{0}(s)} \frac{X_{2}(s)}{X_{1}(s)}=\frac{\omega_{1}^{2} \omega_{2}^{2}}{s^{4}+\frac{c}{m_{1}} s^{3}+\left(\omega_{2}^{2}+\omega_{1}^{2}+\frac{m_{2}}{m_{1}} \omega_{2}^{2}\right) s^{2}+\frac{c}{m_{1}} \omega_{2}^{2} s+\left(\omega_{1} \omega_{2}\right)^{2}}
\end{gathered}
$$

From Figure 3, the transfer function of the transmitted force $F_{\mathrm{t}}$ over $F_{0}$ is

$$
\frac{F_{t}}{F_{0}}=\frac{k_{1} X_{1}(s)\left(\frac{c}{k_{1}} s+1\right)}{k_{1} X_{0}(s)} \cong \frac{X_{1}(s)}{X_{0}(s)}, \text { which is the same as equation (5). }
$$

The $\left(c s / k_{1}+1\right) \cong 1$ at the frequencies of interest and for the damping factors anticipated.

Since most of the interest lies in the frequency response of $F_{t} / F_{0}=X_{1} / X_{0}$, parametric studies involving the gain of this transfer function will be performed here, varying the mass ratio of $m_{1} / m_{2}$, the damping $\mathrm{c}$, and the natural frequency of the cooler mass-spring system. The transfer function in equation (5) consists of 4 poles and 2 zeros. The combined two-mass-spring system causes the two peaks ( 2 double poles) to separate from their respective one-mass-spring natural frequencies of $f_{1}=40 \mathrm{~Hz}$ and $f_{2}=60.8 \mathrm{~Hz}$, respectively. The double zero remains at the balancer resonant frequency of $f_{2}$. From Figure 4(a), it appears that the smaller the ratio of cooler to balancer mass, the further apart the separation of these frequencies on either side of the balancer resonance. The concern was that the higher frequency peak might get into the region of the second harmonic of the cooler drive frequency of $60 \mathrm{~Hz}$, causing amplification of the vibrations at the second harmonic. Examination of Figure 4(a) for reasonable mass ratio 
eliminates this concern. The cooler mass ratio in our setup is on the order of 10. Varying the cooler damping constant in Figure 4(b) changes the overshoot of the low-frequency peak but has no other effect. Lowering the natural frequency of the cooler in Figure 4(c) causes the lowfrequency peak to move down in frequency, and it apparently also changes the damping of this peak.

It is evident from Figure 4(a), (b), and (c) that the transfer function $F_{I} / F_{0}$ has its maximum attenuation at the resonant frequency of the balancer $f_{2}$. This means that the fundamental of the transmitted force will be at its lowest when the cooler is operated at the balancer natural frequency. The attenuation also increases when the natural frequencies of the cooler and the balancer are further separated. However, there are practical considerations in separating these frequencies such as increased balancer mass or intrusion into launch vibration frequencies. Cooler testing confirmed the model predictions that the lowest vibrations are realized when the fundamental drive frequency of the cooler is chosen at the balancer resonant frequency. In this setup, the force, $F_{0}$, was calculated indirectly from acceleration measurements. However, decreasing $F_{0}$ ultimately also decreases the transmitted force, $F_{\mathrm{t}}$, since $F_{\mathrm{t}}=k_{1} X_{1}$ and $X_{1}$ increase as $F_{0}$ increases, with $k_{1}$ constant. Additionally, testing confirmed the existence of two resonant peaks, one on either side of the balancer resonant frequency.

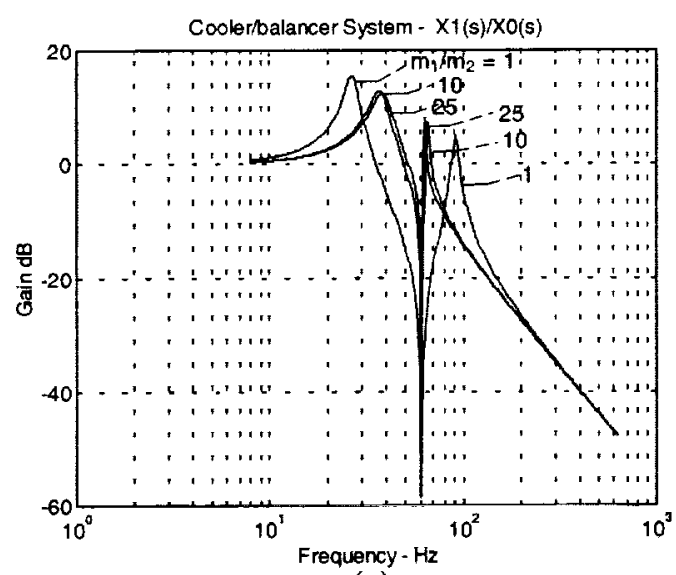

(a)

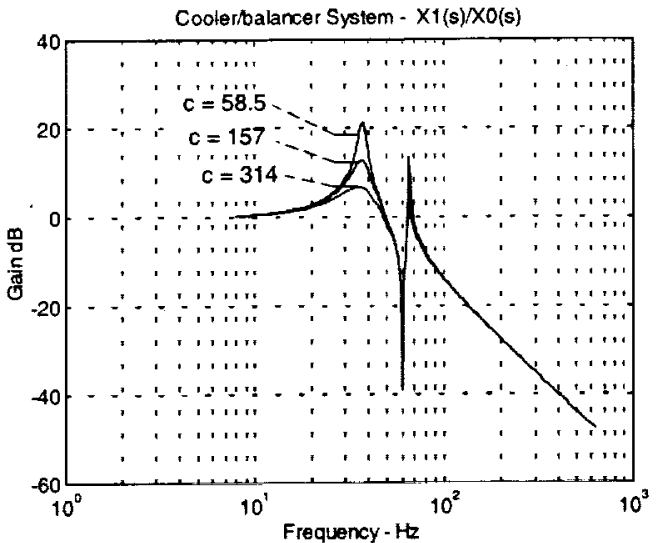

(b)

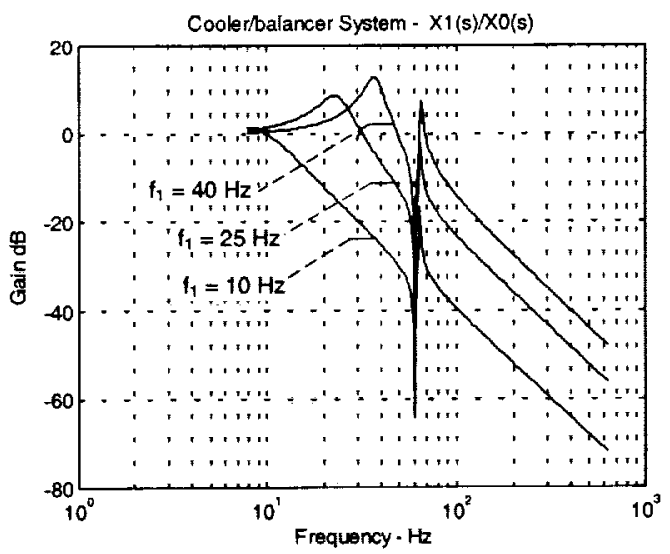

(c)

FIGURE 4. Frequency response of equation (7), varying (a) the mass ratio $\left(m_{1} / m_{2}=1,10,25\right), f_{1}=40$, $\mathrm{c}=157$, (b) the damping $(\mathrm{c}=60,157,314), f_{1}=40, m_{1} / m_{2}=10$, and (c) the cooler mass-spring natural frequency $\left(f_{1}=40,25,10\right) c=157, m_{1} / m_{2}=10$. 

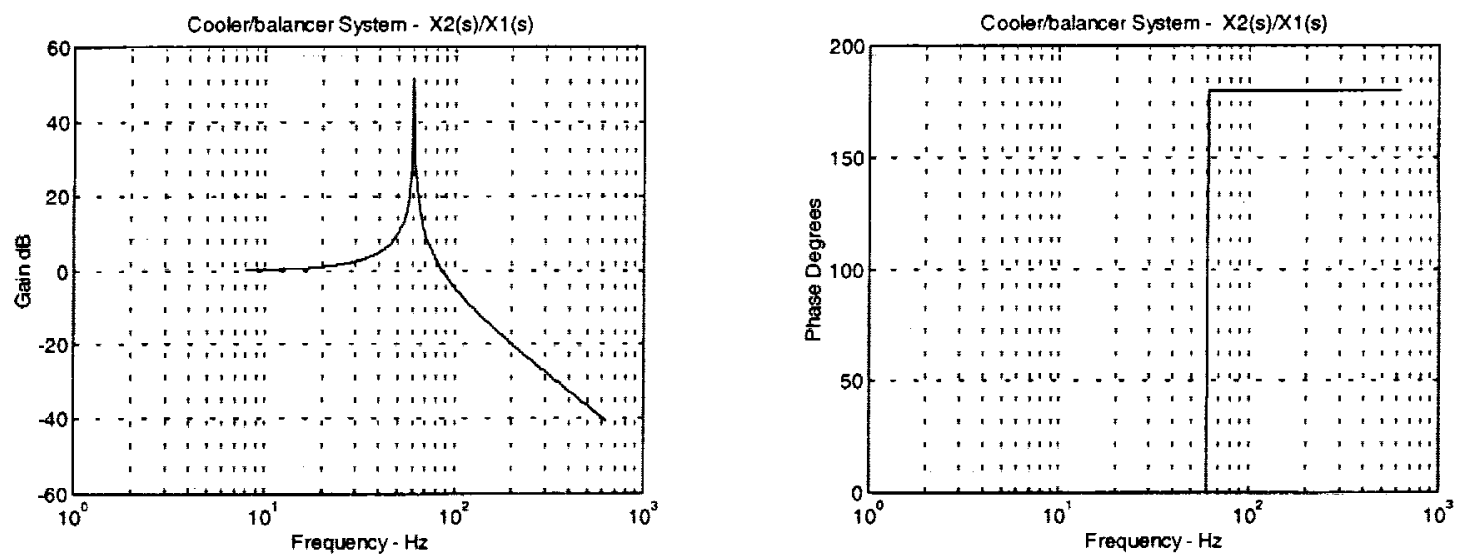

FIGURE 5. Frequency response of equation (3) with $f_{1}=40, f_{2}=60.8, c=157$, and $m_{1} / m_{2}=10$.

Another transfer function of interest is the response of $X_{2}(s) / X_{1}(s)$ in equation (3) shown in Figure 5. Below the resonance in Figure 5, the phase changes from 0 to $180^{\circ}$, which means that $x_{1}$ and $x_{2}$ move from being in phase to opposing phase in this region. However, Figure 5 shows that the transmitted force is attenuated the same way on both sides of the resonance. This may not be exactly what would be expected, as in the case of the opposing coolers, where maximum vibration reduction is achieved when the two pistons are moving $180^{\circ}$ out of phase.

\section{ADAPTIVE VIBRATION REDUCTION CONTROLS DESIGN AND TESTING}

The vibration cancellation signal is synthesized according to the sensed vibrations and superimposed on the power drive signal to the cooler. No active balancer is involved in this process. The LabVIEW control development software is used for signal sensing and control. The hardware control setup is described in the cryocooler testbed section.

The AVRC algorithm is based on an adaptive binary search whereby the algorithm either keeps stepping in a certain direction to minimize a function or performance objective (as long as better results are obtained) or halves the step size and reverses direction (if worse results are obtained). The minimum step size is limited to keep the algorithm continuously active. Figure 6 shows the control diagram of the AVRC binary search algorithm. Unlike the active balancer control approach [2], the AVRC algorithm does not depend on online model identification, which adds complexity. Acceleration vibrations are sensed, and fast Fourier transforms (FFT's) are performed to extract the harmonic spectral content that is needed to synthesize the vibration cancellation signal. Before the algorithm starts, the amplitude of the fundamental waveform is selected. The algorithm adjusts the fundamental frequency until vibrations are minimized at the resonant frequency of the passive balancer. Vibrations are minimized at the balancer resonant frequency because the transmitted force is at its minimum at that point, as described in the previous section. Next, the AVRC algorithm selects the amplitude of the second harmonic vibration cancellation signal and starts adjusting its phase until it minimizes vibrations for this preselected second harmonic amplitude. The AVRC then adjusts the amplitude of the second harmonic vibration cancellation signal, again until vibrations are minimized. This process is followed for control of vibrations from the third harmonic up to the sixth harmonic. Finally, the algorithm loops back to repeat the process. 


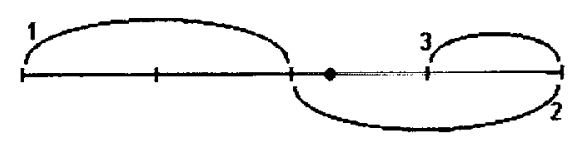

FIGURE 6. Binary search algorithm control diagram.

Figures 7,8, and 9 show, respectively, the spectral density of the peak acceleration with no balancer, with the balancer driving the cooler near the balancer resonant frequency, and with the balancer and the AVRC. The base in these figures is $20 \log _{10}$ and $1 \mathrm{~g}$ acceleration equal to $0 \mathrm{~dB}$. The noise floor was somewhere around $-60 \mathrm{~dB}$. With the balancer in Figure 8 , vibrations at the fundamental frequency decreased by approximately $15 \mathrm{~dB}$. With the AVRC, active vibrations improve by another approximately $15 \mathrm{~dB}$ or 40 times overall, considering that in Figure 9 , the power level was 38 percent greater and vibrations were found to scale proportionally to the power level. More important, the controller found the optimum drive frequency for operation. Without adaptive control, small variations of the balancer mass-spring parameters could result in significant vibration levels because of the sharpness of vibration attenuation at the balancer resonance. The fundamental frequency in Figure 9 shows something like a double peaking. A 60$\mathrm{Hz}$ noise internal to the accelerometer amplifier at the sensing level of approximately $-30 \mathrm{db} g$ was found to be the cause. At different phases, the noise added to the actual vibration level, which caused the measurement and control to jump around. The noise was separated in frequency from the actual vibration signal by increasing the fidelity of the FFT's, and edited out using software. This produced a smooth signal at the fundamental frequency.

It may be possible to achieve significantly greater vibration reduction by taking advantage of the dip in the frequency response, as shown in Figure 4. However, FFT's take a long time to run (a control-sampling time of approximately $5 \mathrm{sec}$ was used). Also, increasing the phase resolution by increasing the data-sampling rate per frequency cycle decreases the frequency resolution for a fixed-size FFT window. In this case, the frequency sensing resolution is approximately $1 \mathrm{~Hz}$. Since the system has a sharp resonance at the balancer resonant frequency, a $1-\mathrm{Hz}$ frequencysensing resolution is not adequate.

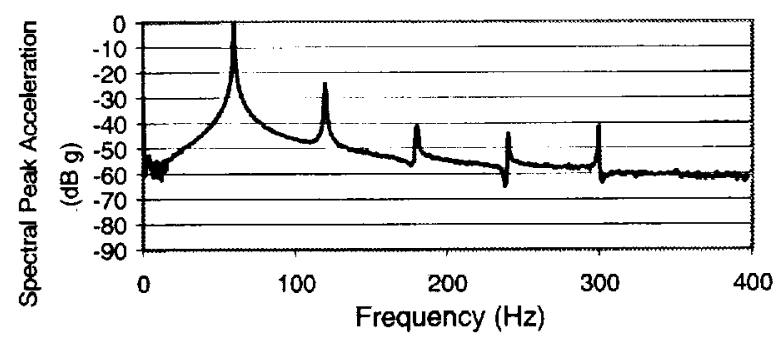

FIGURE 7. Spectral of peak acceleration of cooler $(5 \mathrm{~V}, 2.1 \mathrm{~A}$, and $60.8 \mathrm{~Hz})$ with no balancer.

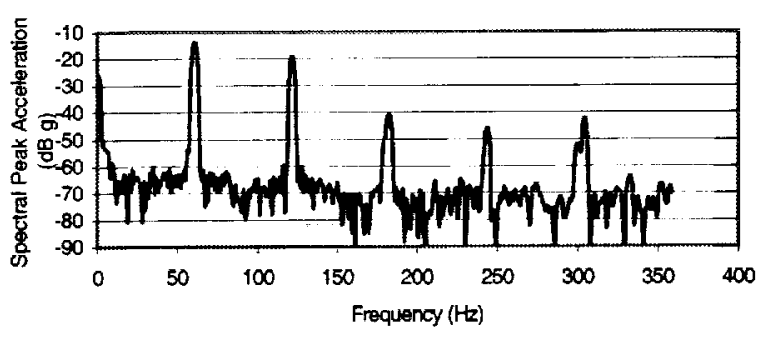

FIGURE 8. Spectral of peak acceleration of cooler with balancer driving the cooler near the balancer resonant frequency $(5 \mathrm{~V}, 2.1 \mathrm{~A}$, and $60.8 \mathrm{~Hz})$.

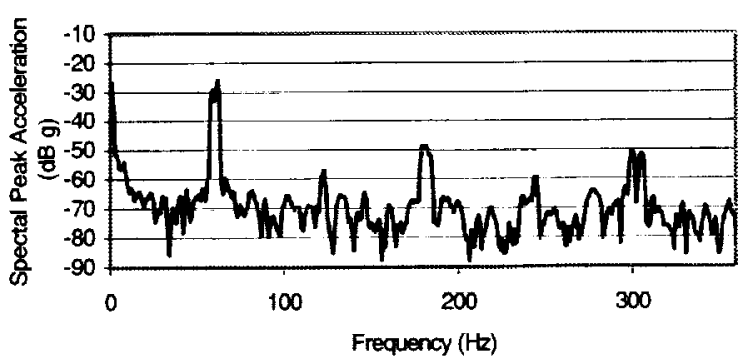

FIGURE 9. Spectral of peak acceleration of cooler-balancer and AVRC (5.0 V, $2.9 \mathrm{~A}$, and approx $60.8 \mathrm{~Hz}$ ). 
The vibration force is calculated as

$$
F_{0}=m_{1} a
$$

where $a$ is the acceleration in $g$ shown in Figures 7 to 9 . With the cooler weight $m_{1} \approx 2.5 \mathrm{~kg}$, the vibration force for the AVRC case in Figure 9 at the fundamental frequency is

$$
F_{01} \approx 2.5 \mathrm{~kg}\left(9.8 \mathrm{~m} / \mathrm{sec}^{2}\right) \log _{10}(-27 / 20)=1.1 \mathrm{~N}
$$

and total force generated is

$$
F_{0}=\sqrt{F_{01}^{2}+F_{02}^{2}+\ldots+F_{06}^{2}} \cong F_{01}
$$

Maximum allowable vibrations for instrument cooling applications are typically on the order of $0.2 \mathrm{~N}$. This level of vibration was previously achieved with control of opposing cooler arrangements using active balancers. It may also be achievable with passive balancer-single cooler configurations by improving the control design and/or introducing mounting arrangements that further isolate the transmitted force.

A temperature controller was also designed and integrated with the vibration controller. This was a proportional integral controller, with the frequency of the controller zero chosen to give a 90-percent response of approximately $110 \mathrm{sec}$. This design was chosen to avoid overdriving the cooler for temperature control and to allow for reasonable dynamic decoupling between the vibration and temperature controllers. The gain of the controller was chosen to give a reasonably damped response.

\section{CONCLUSION}

In this paper, an adaptive vibration reduction algorithm was described for a cryocooler with a passive balancer. The results showed that vibrations were reduced approximately 40-fold with this balancer-controller combination. Employing a vibration-sensing technique other than fast Fourier transforms (FFT's) could improve this control algorithm because of the time required in FFT computation and the frequency resolution needed for this type of control. Improvements to the controls design and/or mounting arrangements that further isolate the transmitted force could result in vibration reduction previously obtained only with active balancer-opposing cooler configurations.

\section{REFERENCES}

1. W.T. Thomson, "Vibration Theory and Applications." Prentice-Hall, Inc.

2. R. Boyle, L. Sparr, T. Gruner, E. James, S. Banks, J. Wilmot, V. Arilo, and T. Gibboney, "Flight Hardware Implementation of a Feed-Forward Vibration Control System for Space Flight Cryocoolers." Eighth International Cryocooler Conference, June 28-30, 1994. 
Public reporting burden for this collection of information is estimated to average 1 hour per response, Including the time for revlewing instructions, searching existing data sources, gathering and maintaining the data needed, and completing and reviewing the collection of information. Send comments regarding this burden estimate or any other aspect of this Davis Highway, Suite 1204, Arlington, VA 22202-4302, and to the Office of Management and Budget. Paperwork Reduction Project (0704-0188), Washington, DC 20503.

\begin{tabular}{|l|l|r|}
\hline 1. AGENCY USE ONLY (Leave blank) & $\begin{array}{r}\text { 2. REPORT DATE } \\
\text { October } 2001\end{array}$ & $\begin{array}{r}\text { REPORT TYPE AND DATES COVERED } \\
\text { Technical Memorandum }\end{array}$ \\
\hline
\end{tabular}

4. TITLE AND SUBTITLE

Adaptive Vibration Reduction Controls for a Cryocooler With a Passive Balancer

6. AUTHOR(S)

George Kopasakis, James E. Cairelli, and Ryan M. Traylor

\section{PERFORMING ORGANIZATION NAME(S) AND ADDRESS(ES)}

National Aeronautics and Space Administration

John H. Glenn Research Center at Lewis Field

Cleveland, Ohio 44135-3191

9. SPONSORING/MONITORING AGENCY NAME(S) AND ADDRESS(ES)

National Aeronautics and Space Administration

Washington, DC 20546-0001
WU-783-82-00-00

8. PERFORMING ORGANIZATION REPORT NUMBER

E-12937

10. SPONSORING/MONITORING AGENCY REPORT NUMBER

NASA TM-2001-211094

\section{SUPPLEMENTARY NOTES}

Prepared for the 2001 Cryogenic Engineering Conference (CEC) and International Cryogenic Materials Conference (ICMC) sponsored by the Cryogenic Society of America, Madison, Wisconsin, July 16-20, 2001. George Kopasakis and James E. Cairelli, NASA Glenn Research Center, and Ryan M. Traylor, Purdue University, West Lafayette, Indiana 47907. Responsible person, George Kopasakis, organization code 5530, 216-433-5327.

12a. DISTRIBUTION/AVAILABILITY STATEMENT

12b. DISTRIBUTION CODE

Unclassified - Unlimited

Subject Categories: 19 and 51

Distribution: Nonstandard

Available electronically at htp://gltrs.grc.nasa.gov/GLTRS

This publication is available from the NASA Center for AeroSpace Information, 301-621-0390.

13. ABSTRACT (Maximum 200 words)

In this paper an adaptive vibration reduction control (AVRC) design is described for a Stirling cryocooler combined with a passive balancer. The AVRC design was based on a mass-spring model of the cooler and balancer, and the AVRC algorithm described in this paper was based on an adaptive binary search. Results are shown comparing the baseline uncontrolled cooler with no balancer, the cooler with the balancer, and, finally, the cooler with the balancer and the AVRC. The comparison shows that it may be possible to meet stringent vibration reduction requirements without an active balancer.

\begin{tabular}{|c|c|}
\hline & $\begin{array}{l}\text { 15. NUMBER OF PAGES } \\
14\end{array}$ \\
\hline & 16. PRICE CODE \\
\hline $\begin{array}{l}\text { 19. SECUAITY CLASSIFICATION } \\
\text { OF ABSTRACT }\end{array}$ & 20. LIMITATION OF ABSTRACT \\
\hline Unclassified & \\
\hline
\end{tabular}

Cryocoolers; Vibrations reduction; Adaptive controls 